\title{
Formation of Art Design Skills (Crossover Point) in the Process of University Education
}

\author{
Tetiana Humenyuk* \\ Received: June 25, 2021; received in revised form: September 16, 2021; \\ accepted: September 17, 2021
}

\begin{abstract}
:
Introduction: The actualization of crossover point design activities in modern artistic practice is due to the growing mass demand for entertainment. The musical and theater project involves the introduction of new technologies. Creation of synthesized art "crossover-projects" requires the efforts of a group of managers and performers, taking into account the demands of the art market, their complex perception by a wide audience, and non-traditional approaches to staging classical works, taking into account the peculiarities of the location.

Purpose: The purpose of the paper is to characterize art "crossoverprojects" in the context of present culture and to reveal the method of preparation of future specialists to art design during getting university education. The article analyzes the methodology of training future specialists for art design in the process of their university education. The need for such an approach is due to the fact that the functioning of artistic culture in public practice is carried out in accordance with the laws of business, in which the commercial component is of decisive importance. Modern art projects have a high cost, as they involve the support and participation of creative individuals and groups.

Results: The growing demand for modern cultural projects containing a creative search, creative component has made it necessary to introduce the corresponding disciplines into the KNUKiM (Kyiv National University of Culture and Arts) curriculum for master students of creative specialties (audiovisual art and production, theatrical art, musical art, choreographic art), as well as design protection of graduation work in the form of a master's creative project. The formation of a creative project within the framework of a master's program is an important element of the formation of skills of the theorist and the practice of artistic culture in their harmonious combination.

Discussion: The phenomenon of design activity - "crossover point" and its distribution in modern artistic practice are characterized. Their polyfunctionalism, "manufacturability" and focus on mass character
\end{abstract}

\footnotetext{
* Tetiana Humenyuk, Kyiv National University of Culture and Arts, Kyiv, Ukraine; t_gumenyuk@ukr.net
} 


\title{
Acta Educationis Generalis \\ Volume 12, 2022, Issue 1
}

\begin{abstract}
induce to creative methods that are not burdened with the experience of the past. Indicative in this respect is the design activity of Filevskaya - art manager, sponsor of many projects dedicated to Ukrainian avant-garde art, founder of the public organization "Malevich Institute". Her work fits into the concept of "crossover projects".

Conclusion: Preparation for art design within the framework of university education provides for the necessary lines of intersection of various art branches, specialties and specializations, encouraging students to create a synthetic artistic product at the intersection of various types of arts and aesthetic and artistic traditions, since the "purity" of art is no longer a criterion for creativity and professional success.
\end{abstract}

Key words: design activity, "crossover point", art projects, synthesis of arts, design in the field of culture.

\section{Introduction}

Actualization and dissemination of design activities in modern art practice is due to the growing mass demand for entertainment. A musical-theatrical project is a new form of creative activity that involves a combination of several arts and is based on use of new technologies. Creation of synthesized art "crossoverprojects" requires the efforts of a group of managers and performers, taking into account the demands of the market of artistic needs, their comprehensive perception by a wide audience, unconventional approaches to producing classical and modern plays according to location. Art culture functions in modern social practice in accordance with the laws of business, in which the commercial component is important and sometimes crucial. The cost of modern art projects is quite high, because their implementation requires the support and participation of creative individuals and groups. Appeal to creative techniques, not burdened by the experience of the past, provides it (projects) multifunctionality, "manufacturability" and focus on the masses. Stanislavska (2016), Saenkova (2003), Sklyarova (2017) study different types of spectacles, as well as the latest trends in the development of entertainment culture due to the latest information technologies.

Training of specialists in art design within the university education involves provide the necessary intersections of different arts, encouraging students of several specialties and specializations to create a synthetic art product at the intersection of different arts and aesthetic traditions, because the "purity" of art genres is no longer a criterion of creativity and professional success.

\section{Research}

With the development of media and communication technologies, the leading trends in the culture of the early 21 st century, the difference between elite and 


\section{Acta Educationis Generalis \\ Volume 12, 2022, Issue 1}

mass art is practically leveled. The traditional art forms and artistic practices are influenced by mass, popular culture. The desire to meet the mass demand for entertainment gives rise to synthesized artistic "crossover projects". Goal and tasks of the article - to characterize art "crossover-projects" in the context of present culture and to reveal the method of preparation of future specialists to art design during getting of university education.

In their origins, these phenomena are connected with the concept of "Gesamtkunstwerk" by Wagner - the synthetic art of the future, with the idea of the future synthesis of Scriabin - "auditory polyphony" (auditory), with "sessions" by Mallarmé, with the art of "eurythmy". Steiner, with compositions by Kandinsky, etc. At the beginning of the 20th century, these ideas brought to life spectacles, complex in structure, designed for a comprehensive perception of a fairly wide audience. Such artifacts are created by the efforts of a group of managers and performers in accordance with the demands of the art market.

Characterizing such art projects, it is worth noting, first, that they do not have clear genre features, and secondly, they widely use up-to-date technical means of expression and non-traditional plays of classical works, taking into account the peculiarities of the location, which dictates the techniques needed to solve a particular artistic problem.

The project is a plan, idea, development, etc. (Dictionary of foreign words, 2008). Borrowed from technical disciplines, in the practice of the art market it has acquired a new meaning: it is not only a plan, but also an idea, preparation and implementation in various formats of "consumption" of a work of art. Thus the etymology of the word sometimes comprehensively reproduces the basic meanings of being, real and possible. The concept of "crossover-point" translated from English means the point of intersection, crossroad and crosscombination, it appears as a methodological principle in the study of the synthetic nature of art projects common in modern cultural and creative activities. This approach enables to consider multi-vector and multi-sectoral activities in their synthesis, which creates a model ("ideal type") of a modern art project. The logic of the theory of "crossover point" encourages to "fit" the design activities into the cultural context, to identify such conceptual aspects as "cultural potential", "socio-cultural demand", "aesthetic-artistic and ethicaleducational orientation", "commercial component", "recreational-interesting component", etc. In the context of art culture, the term "project" is understood not as a certain original plan, but as a unique set of coordinated experimental actions of masters of art culture, combined for a certain time within a certain cultural location to solve specific artistic problems.

The availability of art culture in present conditions, including classical, is carried out in public practice in accordance with the laws of business, in which the commercial component, as well as the role of the producer, are crucial. The producer's work in the project combines commercial and aesthetic-artistic components: it defines the tasks and functions of the means of expression, the 


\section{Acta Educationis Generalis \\ Volume 12, 2022, Issue 1}

role of conditions in which a certain artistic action will take place, the audience, the duration of the project life cycle attracting modern technologies.

As is know, a certain number of spectators turn to classical art for cognitive purposes - to get important information and gain new sensory experience. For them, this is an opportunity to learn about high culture. At the same time, the creation of design plays on the models of world classics is a promising way to form a world artistic "crossover" - space - in fact, the space of spirituality.

Classical art, including music, has entered the modern media-communicative space quite organically, in which both the music of the "third layer" (jazz-rockpop music and classical, available here in the form of transcription), paraphrases, processing or free reading, and re-intonation is widespread, etc. Due to this, the modern musical-theatrical project, created on the basis of classical repertoire, including opera, acquires new features, including features of the spectacle "crossover" - character, modern mass culture addressed to the widest possible audience. Among them there are only a small number of connoisseurs and admirers of high art.

Its implementation requires not only producers, directors, performers, but also the appropriate audience, ie mobile, limited in a certain space-time composition of implementers-performers-receivers, built within a certain specially selected location, suitable for this action. In addition, the established, stationary forms of existence of a certain art form are undergoing changes. The spatiality of the project is its constant feature, which presupposes the ordering of all other components.

According to the Dutch philosophers Timothy Vermeulen and Robin van den Acker, the currently applied principles of the organization of the artistic space are the defining features of the goal of modernism. They believe, if modernism expresses itself through utopian syntax, then postmodernism, through hopeless parataxis, metamodernism, obviously expresses itself as an a-topical metataxis. The Greek-English lexicon translates atopos ( $\alpha \tau 0 \pi \mathrm{o} \varsigma)$ as strange, extraordinary, and paradoxical. However, most theorists and critics insist on its literal meaning: a place (topos) for which there is no place. We can thus say that the atopos is both a place and a non-place, a territory without borders, a position without borders. We have already described metataxis as being here, there and nowhere at the same time. In addition, taxis ( $\tau \alpha \dot{\xi} \xi 1 \zeta)$ means ordering. Thus, if modernism presupposes temporal ordering and postmodernism a spatial disorder, then metamodernism should be understood as space-time, which is at the same time neither in order nor in disorder. Metamodernism replaces the boundaries of the present on the verge of the infinite future; replaces the boundaries of familiar places with the description of the infinite. In fact, this is the "fate" of metamodern man: to pursue horizons that recede endlessly (Vermeulen, \& van den Acker, 2015).

In the context of these reflections connected with creation of artistic projects, the most significant is the tendency to find and use experimental hubs, including a 


\section{Acta Educationis Generalis \\ Volume 12, 2022, Issue 1}

modern exhibition center, museum site, city center - from ancient ruins to specially built summer theaters, parks, etc. as intersections of various cultural loci (artistic, public, hierotopic, etc.). So, it is about solving specific tasks of the original art project.

This captures a situation in which a new round, a leap in the development of key ideas in culture, similar to those common at the end of the last century. According to the Latin proverb ("after - means due"), it can be argued that after and due to postmodernism in the culture of the 21st century, the position of playful, but not gambling, but calm, without pathos, sorting out cultural variants of previous eras, when unambiguous choice does not only make sense - it is simply not possible. This is an ideology that "justifies" a new erosion of "repressive" boundaries and limits between species, genera, genres, and most importantly - between forms of cultural activity. A new state of culture, when not only lyrics, epics and drama, not only poetry, painting, theater and other arts, but also creativity and business, performers and the latest technologies are eclectically combined.

Despite the "youth" of various manifestations of design activity in art, it is these phenomena that form today the "tonatmosphere" of the cultural life of society. Without these, sometimes unexpected, one-time cultural and artistic actions, it is impossible to imagine the worldview, mentality, well-being of the "avant-garde layer" of the intellectual elite, creative personalities who embody the certain features of mass consciousness in (post-) industrial society.

So, we enter the (super-, post-) information society and similar phenomena reflect its, perhaps, the first (yet immature) phase, when adequate ways of "taming" the arbitrariness, selfishness and greed of media owners are practiced, unprincipledness of critics and journalists, when feedback is established between consumers of information and its producers, when the intellectual and moral level of consumers does not yet ensure their influence on these processes.

Such changes in culture are very slow. Since the end of the 20th century, with the beginning of the information age and transformations in the field of culture, due to modern information technology, the number of figures in the field of mass communication and "current" culture has increased unprecedentedly. Now, the deformation of cultural activity, unique in its scale and depth, has unfolded. On the one hand, it resembles the "feuilleton era" described by Hesse (1969, p. 46) in his novel The Game of Beads: "It was then that terrifying insecurity and apathy began to spread among intellectuals; and spiritual needs and achievements rapidly fell to a very modest level." And further: "The path to public recognition, honor, fame and comfort now leads not through classrooms, seminars and doctoral dissertations: extremely declining intellectual professions then went bankrupt in the eyes of the world... Those talents, who sought brilliance and worship, were destined to turn away from boredom ungrateful spirituality and devote themselves to other activities in which their destiny was to earn money and prosperity." (Hesse, 1969, p. 56) 


\section{Acta Educationis Generalis \\ Volume 12, 2022, Issue 1}

On the other hand, the worldview and thinking of man at the beginning of the new millennium is undoubtedly more meaningful. This leads to the analysis of the game as a cultural phenomenon, started by Geising and actively continued by foreign and domestic researchers in modern cultural discourse.

"Gamification" ("grogification") permeates and transforms the modern cultural space, encouraging the interactivity of all participants in the process of cultural creation. It should be noted that in Scandinavia, game forms in school and university forms of education have long been recognized at the legislative level. These questions arise every time you reflect on the radical changes in culture that we are witnessing and that appeal to the long-standing debate about the role of play in culture. Some experts consider the game a cultural element; others are convinced that the game devalues the serious in culture and art.

In this regard, the opinion of a famous scientist about the activities of modern museum institutions as components of the socio-cultural sphere cannot fail to attract attention. It can rightly be extended to cultural and artistic institutions. Tomislav Shola in his work "Eternity does not live here any more. A glossary of museum sins." Shola (2013) emphasizes that the modern spectator, listener, visitor of the museum, concert hall, exhibition, seeks to feel a participant in dialogue, communication, during which elements of education and entertainment, emotional uplift are used and rich informativeness, after all, of art and real life. It is, in fact, about the gamification (gamification) of cultural activities, about the introduction of the game in a non-gaming context. This experience has entered the modern artistic discourse and radically changes the principles of current cultural and artistic practice.

The state and needs of artistic culture, the scientific and technological revolution that began in the second half of the 20th century, underwent informational and later electronic transformations, today they are in the phase of "nanorevolution", creating fundamentally new conditions not only for changing genres of art culture, and their embodiment. New technologies have contributed to the unification and, subsequently, the globalization of artistic processes. Nowadays we can talk about new formats of "consumption" of artistic products, directly due to the latest technologies, about their entry into the cultural and artistic market.

To create such artistic products, in addition to authors and performers, a new community of interdisciplinary specialists is needed (and accordingly already formed). It turned out that the profitability of the creation of the created artistic product increases significantly if it is produced in different formats of consumption. Therefore, around the creative group of authors and performers began to form a team of managers under the leadership of the producer as the main person who takes all the risks possible during the life cycle of the creative idea. The figure of the producer begins to play the role of regulator of economic relations. The process of planning, creating and implementing a set of 


\section{Acta Educationis Generalis \\ Volume 12, 2022, Issue 1}

synthesized cultural and artistic products, united by a common concept, has been known as a project.

A. Maslow, a well-known researcher on the "self-actualization" of personality, said in particular: "We must understand that the future is the only thing that is in principle unknown and unknowable, which means that all habits, all mechanisms of defense and attack - are questionable and have a double meaning because they are based on past sensations. Only a flexible creative person can truly control the future, only such a person can confidently and fearlessly look in the face of novelty." (Maslow, 2016, p. 6). These words convince us how seriously in modern cultural theory in the conditions of the end of "despotism" of any form, especially in art, such phenomena are comprehended.

Now, the established tradition of depriving an object of the context in which it is perceived, "pulling" it out of the environment, cutting off natural connections with space-time, in which certain actions, actions, events of cultural and artistic significance take place, loses its indisputability. After all, as Shola (2013, p. 37) writes: "Without a 'broth' of myths, beliefs, ambitions, aspirations, life, historical events and destinies, in which objects are usually immersed (whether art actions, events... - we will add), they mean little."

The concept of context has become a key in understanding the existence of art in the situation of the" beginning of the century ". It can now be argued (according to Nelson Goodman, whose ideas form the basis for further philosophical modeling of the world) that knowledge of the plurality of worlds, their dependence on the symbolic systems we construct, the diversity of standards of correctness to which our constructions obey in the Preface to "Ways of Building the World" emphasizes: "This book belongs to the dominant trend of modern philosophy, which began when Kant replaced the structure of the world with the structure of consciousness, continued, when K. I. Lewis replaced the structure of consciousness with the structure of concepts, and when the replacement of the structure of concepts with the structure of several symbolic systems of science, philosophy, art, perception, and everyday discourse began. This movement is directed from one single truth and one from the beginning of this world to the process of generating a variety of correct and conflicting options or worlds." (Goodman, 1968, p. 5).

At the turn of the 19th and 20th centuries, the American sociologist Veblen introduced into scientific circulation the concept of demonstrative consumption. In this way, he signified the desire of man to receive everything at the highest price and, thanks to this type of consumption, to join the elite samples of artistic products, which are considered "filters for sifting the elite." Attending prestigious art events confirms the idea of a slow but relentless process of popularizing elite taste. This leads to a gradual mixing and intertwining of those social institutions and forms that were previously considered mutually exclusive. The cultural industry is also reorienting to this type of consumption. Thus, a high-quality art project can significantly affect public life with its 


\section{Acta Educationis Generalis \\ Volume 12, 2022, Issue 1}

multidirectional, synthesized, syncretic, large-scale nature; long remain in the memory of the target group for which it was intended.

Art project can be considered relatively separate, holistic activity. It is based on the latest artistic idea, and at the same time - a certain innovative and technological idea, a clear calculation of efficiency in direct connection with the algorithm to achieve the goal due to appropriate resources and performers, i.e. factors of tangible and intangible nature.

Art projects have a high "cost", because their implementation requires the involvement of various spheres of society, support and participation of creative individuals and teams. Hence the purpose of such art projects - to create aesthetic, artistic and moral-educational communication space, to educate people "cultural". The authors of these projects depart from any clear genre and style criteria and resort to individual decisions in accordance with a certain goal, choosing the appropriate means of expression. It is another matter that the historical and cultural aspects of each project actualize other types of human artistic activity: from ancient plays - theater, music, even "agon", to medieval liturgies, mysteries and carnivals, to classical art and spectacles of New times, and finally to modern and postmodern manifestations of artistic culture.

A modern art project, which includes, among other things, the introduction of the latest audiovisual technologies, promotes the spread of new, global art genres or meta-genres (gala concerts, light and sound performances, electronic extravaganzas, cinemasymphonies and other synthesized-syncretic plays), which not provided for traditional classification. These art projects perform aesthetic and ethical-educational, recreational and training functions.

The design activities of Tetyana Filevska, art manager, sponsor of many projects dedicated to Ukrainian avant-garde art, founder of the public organization "Malevich Institute" can be considered as indicative. Her work fits directly into the concept of "crossover-projects", because it corresponds to the main principle - the synthesis of several activities: art-search, art-education and art with the creation of a locus of events. Its diverse projects connect both the professional expert community and the general public. Polyfunctionality, cultural nature of art projects, their "technological" and focus on the masses encourage to resort to creative techniques not limited by the experience of the past. Such guidelines and principles are fully embodied in her project work of Filevska, which began with the discovery of "Ukrainian Malevich": the reconstruction of the artist's biography of teaching at the Kyiv Academy of Arts with subsequent immersion in the "biography" of the artist, full of Ukrainian realities. The question arises: why the interest in the creative biography of the great artist prompted her to project activities? In fact, this is the difference between Filevska as a researcher and many other biographers of the artist. The answer is obvious - she creates an extensive network of projects around scientific research precedent (which is the search and analysis of new archival materials, cultural connections and contexts) - actions, creative competitions, publishing, exhibitions, lectures, seminars with 


\section{Acta Educationis Generalis \\ Volume 12, 2022, Issue 1}

their information support and establishing an appropriate mechanism of interaction, PR (within both domestic and foreign institutions) (Statute of the community organization "Cultural Assembly, 2016, p. 32). This crossover paradigm of projects gives fruitful results and arouses interest: any cultural event turns into "fashionable" prestigious content, launching in one location a synthetic machinery of ideas, personalities, events, arts. For example, the international conference of 2016 "Kazimir Malevich: Kyiv aspect" was organized and held, which did not "fit" into the usual model of such events. On the contrary, the Malevich Institute managed to properly organize and hold several daily celebrations (in various cultural locations in Kyiv). The organizers invited representatives and figures of different cultural and artistic spheres to participate, created a synthetic action based on different types and genres of art: painting, music, cinema, the newest media, and design installations. This created a background for intellectual content and communication. The informational coverage of the project also seems unconventional due to the proper discursive platform, which helped to transform the intellectual event into a unique cultural and artistic event that interested and encouraged the public.

The activity of the Malevich Institute gives an opportunity not only to discover and understand the essence of various cultural and artistic projects; it encourages new project ideas, to determine the perspective of cultural creation.

\section{Results}

The growing demand for modern cultural and artistic projects, which contain creative and exploratory, the latest creative component, prompted to introduce into the KNUKiM's curriculum for graduates of master's degrees in creative directions of relevant subjects (audiovisual arts and production, theater, music and dancing) also design-defense of qualifying work in the form of a master's creative project. Developing a creative project within the master's program is an important form of acquiring the skills of a theorist and a practitioner of art culture in their harmonious combination. Often the weakest link in this design is to convey the main idea to the "customer", its actualization and specification of resources and means of implementation. The main attention at this stage is paid to the definition of such a component as "concept-implementation". This line is complicated by the involvement of synthesized elements in the production of the project. So, the students must demonstrate mastery of modern art practices, as well as technologies for creating the so-called conceptual package, which provides for the availability of scientific publications in Ukrainian and foreign specialized scientific journals, abstracts at international and national conferences, symposia and round tables. These materials should contain a theoretical substantiation of the main idea of the project, an understanding of the axiological significance in the model of a particular cultural situation, as well as reveal the history of the origin and development of the concept and possible 


\section{Acta Educationis Generalis \\ Volume 12, 2022, Issue 1}

options for its current and future development. This conceptual training is due to the fact that the modern project involves the intersection (crossovers) of different approaches, principles, the synthesis of which provides a new artistic product.

Masters must acquire professional skills to independently apply the acquired knowledge in solving specific artistic, scientific, organizational and other tasks. It is necessary to recognize the dialectical interaction of these areas of work, which, according to teachers-managers of project activities of KNUKiM students, is impossible within such a sequence. In some cases, the procedurality of the full creative cycle is due to the fact that students start from seeing and understanding the essence of the final product, and then find the "reverse" way to its conceptual core. In other variants, on the contrary, theoretical, conceptual competence encourages the creation of original project works. In each case, the important element is a way (here and the method) of independent implementation (ie practical implementation) of the idea, originality and expediency of creative solution. But most importantly, the project should convince that it is not only important for the creators, for the department and faculty, but also meets modern socio-cultural needs. In fact, this is the so-called socio-cultural value of the project.

\section{Discussion}

Implementation of art design within university education allows the necessary lines of intersection (again, social crossovers) of different arts, specialties and specializations, to adhere to the necessary conditions of modern artistic career to prepare and encourage students to create a synthetic (therefore relevant) art product at the intersection of different types of arts and aesthetic and artistic traditions ("purity" of art is not a modern criterion of creativity and professional success). Therefore, the master's project is a great opportunity for such a professional synthesis-crossroads.

It should be noted that the design approach to the preparation of master's theses is fundamentally different from the traditional openness to further creative and professional implementation in today's creative industries. It is constructed as a matrix-principle, the application of which is universal. In addition, the new principles of preparation of a creative project led by theorists and practitioners form an ideal model for combining research (analytical and theoreticalmethodological) and experimental (practical) work. Each master's project is demonstrated publicly, accompanied by an explanatory note and a complete conceptual package, and has an indicator of effectiveness as an accomplished rather than a traditional "stillborn" due. The artistic professionalism of graduates, which the university strives to achieve as the ultimate goal of the educational process, is manifested in the fact that they do not avoid the naturalness of life's drunkenness and unprogrammed creative. Focus on design is a living 


\section{Acta Educationis Generalis \\ Volume 12, 2022, Issue 1}

combination of ideas, intentions, skills, beliefs and professionalism of the "university corporate mind".

\section{Conclusion}

Thus, the term "project" in the context of artistic practice means not only as a result of the original plan, but as a unique set of coordinated actions aimed at achieving a specific cultural, aesthetic and artistic goal. Throughout history, there is an active search for new forms of artistic creativity to reflect and comprehend the changing reality. Art projects have become a logical manifestation of cultural development. Design activity in the field of culture at a new level "connected" Ukrainian art to world art trends, fully changed the picture of the existence of Ukrainian art culture. Art projects are a new form of syncretic-synthesized play and phenomenon mediated by the peculiarities and realities of world culture of the early 21 st century.

Finally, here are the words of the prominent philosopher Ortega y Gasset: "The Faculty of Culture produces a certain type of scientific character, which previously developed by chance - integrative talent" (Ortega y Gasset, 2005, p. 59]. This talent, as the Spanish thinker explains, lies in the ability to create integrity. In the context of the article, "design integrity" is understood as intersections of design construction of ideas and their results ("crossover points"), multi-vector, but aimed at the current future, which reveal the potential and social significance of cultural and creative practice.

\section{References}

Goodman, N. (1968). Languages of Art. An Approach to a Theory of Symbols. New York: The Bobbs-Merrill Company.

Hesse, G. (1969). The Glass Bead Game. Moscow: Art. lit.

Huizinga, J. (1994). Homo Ludens. The Experience of Determining the Game Element of Culture. Kyiv: Osnovy.

Maslow, A. Kh. (2016). Motivation and Personality (3rd edition). St. Petersburg: Peter.

Ortega y Gasset, H. (2005). Mission of the University. Minsk: BSU.

Shola, T. (2013). Eternity Does Not Live Here Any More: Explanatory Dictionary of Museum Sins. Retrieved from https://www.academia.edu/42670145/Eternity_Does_not_Live_Here_Any_ More_A_Glossary_of_Museum_Sins Saenkova, L. P. (2003). Mass Culture: The Evolution of Spectacular Forms. Minsk: BSU.

Sklyarova, V. C. (2017). Visual turns and entertainment culture: Theoretical aspects and cultural practices. Bulletin of Culture and Arts, 4(52), 116-120.

Stanislavska, K. I. (2016). Art and Entertainment Forms of Modern Culture: Monograph (2nd revised edition). Kyiv: NACCKiM.

Statute of the Community Organization "Cultural Assembly. (2016). Kyiv.

Vermeulen, V., \& van den Acker, R. (2015). Notes on metamodernism. Metamoden. A Journal about Metamodernism. Retrieved from http://metamodernizm.ru/notes-on-metamodernism/ 